\title{
Composite fabrication from fat extracted limed fleshing: solid waste management in tannery
}

\author{
M. A. Hashem*, M. H. R. Sheikh, Rahamatullah, M. Biswas, M. A. Hasan and S. Payel \\ Department of Leather Engineering, Khulna University of Engineering \& Technology, Khulna 9203, Bangladesh
}

Received: 23 June 2021

Revised: 18 July 2021

Accepted: 23 August 2021

DOI: https://doi.org/10.3329/bjsir.v56i3.55969

\begin{abstract}
In tannery, fleshing is the unavoidable solid waste which has negative effect on the environment. Fleshing contains fat, and protein.In this work, fat extracted fleshing was used for composite fabrication. After collecting limed fleshing, fat was extracted in water bath.The fat extracted fleshing was dried, ground,passes through 80-mesh and homogenized.For proper adhesion and bonding with fleshing powder, epoxy resin and hardener were mixed at various ratios and poured onto an aluminum sheetfor $24 \mathrm{~h}$ curing. The mechanical properties of the composite were investigated by tensile strength, elongation at break, and Young's modulus. The composite was characterized by Fourier Transform Infrared (FTIR) Spectroscopy and Scanning Electron Microscope (SEM) for related functional groups and surface analysis. The investigation provided satisfactory information on the proper bonding of the fleshing powder and resin/hardener. The approach explores the valorization of he waste for managing solid waste in the tannery.
\end{abstract}

Keywords: Fat extracted fleshing; Composite; Tannery; Young modulus; Tensile strength

\section{Introduction}

Recycle-reuse-reduce (3R) are three great ways of eliminating waste to protect our environment. An industry-only could survive if it maintains the $3 \mathrm{R}$ ways. Though the contribution of leather industry to the country's economy is significant, it has gradually become a burden due to its enormous amount of pollution creation.From each operation of leather processing huge amount of liquid, gaseous and solid waste generates (Anupama and Rubina, 2013). Inapt disposal of solid waste not only pollute the environment but also create an adverse effect on human health. Due to environmental regulations, many countries are going to stop leather processing because of the production of high pollutants (Sundar et al.2011). It is estimated that from $1000 \mathrm{~kg}$ raw hide approximately $850 \mathrm{~kg}$ solid generates among which 80 percentages comes from the beam house operation.Among these $80 \%$ of beam house solid waste 50-60\% comes from the fleshings (Kanagaraj et al. 2006). Other solid waste includes keratin waste, skin trimmings, buffing dust, chrome splits, chrome shaving. The produced huge amounts of solid wastes from the tannery are classified as non-proteinous, collagenous untanned, and collagenous tanned (Sekaran et al., 1998). Due to a lack of proper management options, these solid wastes are disposed of here and there and pollute the environment.These types of solid waste also pollute the roundwater when the rainwater washes them away.

In the last decades, several techniques have been introduced to reuse, minimize, reduce and recycle these solid wastes (Parvin et al, 2017). 
Landfilling is the most convenient method to manage tannery solid waste which is not considered an effective method as the improper design of the landfilling tank may lead to water and soil pollution through leaching (Patel and Patra, 2014). The incineration process could reduce the final volume of the solid waste but during the incineration process different toxic gases like nitrogen oxides, sulfur dioxide release which further pollutes the environment (Tang et al., 2008). By using different microbiological enzymes hazardous solid waste can be converted into valuable products but microorganisms required an especial environment for its efficiency (Dhal et al., 2013). Polizzi et al. (2018) reported that tannery fleshing could be converted to biogas through anaerobic digestion. The main disadvantages of anaerobic digestion are that it creates odors problems and for the survival of different microorganisms definite percentage of nutrients have to provide in a regular interval. Hashem and Nur-A-Tomal (2017) claimed that glycerin, soap can be produced from the extracted fat of leather fleshings waste. During unhairing and liming operation of leather processing, the hide/skin is treated with lime and sodium hydrogen sulfide to remove hair and other interfibrillary protein from the hide/skin as well as swell up the hides and skins. Fleshing operation is carried out after the unhairing and liming stage where the flesh and fat part of the hide and skin are removed mechanically. The main constituents of the fleshing waste are $5-7 \%$ of protein, $4-8 \%$ of fat, $2-6 \%$ of lime, and $1-3 \%$ of sulfide (Lupo, 2006). Due to the presence of a large number of fats and protein fleshing can be used as raw materials for biodiesel production (Š́nek et al. 2015). Besides several researchers used leather fleshing waste for the production of biogas (Ravindranath et al., 2010), compost (Ravindran and Sekaran, 2010) and feed ingredients (Rai et al., 2010).

In this study, an approach was made to fabricate composite material from the fat extracted limed fleshing to reduce the disposal load from the tannery. The physical properties of the composite were performed to ensure quality. The novel approach would be able to offer a sustainable answer for tannery waste management.

\section{Materials and methods}

\section{Sample collection}

Fresh cowhide fleshings were collected from a local tannery house in Khulna, Bangladesh after the unhairing and liming operation. The fleshing is known as limed fleshing. The fleshing was soft, pliable, and patchy. Hashem and Nur-A-Tomal (2017) claimed that the limed fleshing contains $66.3 \%$ moisture and $9.1 \%$ total fat content.

\section{Chemicals and reagents}

Commercial boric acid and commercial hydrochloric acid were used as deliming agents and were collected from a local scientific store in Khulna, Bangladesh. The standard epoxy resin (Araldite AW106, India) and hardener (Araldite HV 953 IN, India) were procured from Khulna, Bangladesh. Epoxy resin is a very popular adhesive material which can bond various metal, rubber, glass, ceramics, plastics, etc. This adhesive contains acrylic, polyurethane, cyanoacrylate, and one of the highest performing adhesives. It is also known as 'engineering adhesive' or 'structural adhesive' (Murugan et al., 2021). Table I represents the properties of epoxy resin (Araldite AW106) and hardener (Araldite HV 953 IN) (Guduru et al., 2021).

\section{De-liming offleshings}

The limed fleshing sample contains lime and sodium hydrogen sulfide utilized during liming operation. To enhance the fat extraction operation, deliming was carried out. At first, free lime present in the fleshing was washed out with water. Then it was chopped into small-sized pieces to continue to the next stage. The cut pieces of the fleshings were treated with boric acid $(2 \%, \mathrm{w} / \mathrm{w})$ and water $(60 \%)$ and continued the

Table I. Properties of epoxy resin (Araldite AW106) and hardener (Araldite HV 953 IN)

\begin{tabular}{lccc}
\hline Parameters & Unit & Araldite AW106 & Araldite HV 953 IN \\
\hline Color & visual & neutral & Pale yellow \\
Specific gravity & $\mathrm{g} / \mathrm{cm}^{3}$ & approx. 1.15 & approx. 0.95 \\
Viscosity at $25^{\circ} \mathrm{C}$ & $\mathrm{Pas}$ & $30-50$ & $20-35$ \\
Mix ratio & $\mathrm{w} / \mathrm{w}$ & 100 & 80 \\
\hline
\end{tabular}


process to separate the lime from the fleshings.Hydrochloric acid was added to the delimed fleshings to adjust the $\mathrm{pH}$ at 6-7. Finally, the fleshings were water washed for a second time.

\section{Fat extraction}

For fat extraction, Hashem and Nur-A-Tomal (2017) method was followed. In this case, the delimed fleshings were heated in a water bath at a 1:1 ratio of fleshing and water for a long time until the fat is separated from the fleshings. To separate the fat and water, a separating funnel was utilized which freed the fat from an aqueous state. After that, the residual water in the fat was distilled off. It was found that $6.2 \%$ fat can be extracted based on dry weight at optimized conditions ( $75^{\circ} \mathrm{C}$ at $3 \mathrm{~h}$ ) (Hashem and Nur-A-Tomal, 2017).

\section{Drying of fat extracted fleshing}

After the fat extraction, the remaining fleshing, termed as 'fat extracted fleshing' was at first sun-dried and then oven-dried at $105^{\circ} \mathrm{C}$. Finally, the dried fleshing was ground with laboratory mortar to make granules and sieved with 80 mesh to have a uniform powder.

\section{Fabrication of composite}

To fabricate the composite material, the fat extracted fleshing ground (FG) was separately mixed with the epoxy resin and the hardener at different ratios and mixed them well. Then,the mixture was poured into an aluminum sieve and kept overnight for curing.

\section{Fabrication process optimization}

Experiments were carried out to optimize the composite fabrication process e.g., a fixed amount of FG with the ratio of epoxy resin and hardener (epoxy resin: hardener-2:1). Five predefined ratios of the FG, resin, and hardener were used for composite fabrication. The ratio of composite fabrication is shown in Table II. The epoxy resin and hardener ratio was fixed because of the manufacturer guide. In each ratio (FG: resin: hardener), three composites were fabricated.

\section{Physical properties of fabricated composite}

The fabricated composite material was assessed for tensile strength $\left(\mathrm{N} / \mathrm{mm}^{2}\right)$, elongation at break (\%) and Young's modulus. The composite properties were measured following the standard method of ASTM: D225 using Universal Testing Machine (UTW, WAW-2000E, India). Triplicate measurement was performed for average and standard deviation. Finally, the tested data were used to calculate the value by the Eq. (i), Eq. (ii), and Eq. (iii).

$$
\begin{aligned}
& \text { Tensile strength }\left(\mathrm{N} / \mathrm{mm}^{2}\right)=\frac{\text { Breaking load }(\mathrm{N})}{\text { Thickness }(\mathrm{mm}) \times \text { Width }(\mathrm{mm})}-\text {---- (i) } \\
& \text { Elongation at break }=\frac{\mathrm{L}_{1}-\mathrm{L}_{0}}{\mathrm{~L}_{0}} \times 100 \text {------ (ii) }
\end{aligned}
$$

Where $\mathrm{L}_{0}=$ the initial distance of jaws/sensors and $\mathrm{L}_{1}=$ distance at the break of jaws/sensors

$$
\text { Young's modulus }=\frac{\text { Sress }}{\text { Strain }}
$$

\section{FTIR (Fourier Transform Infrared Spectroscopy) analysis}

FTIR(FTIR 1600, PerkinElmer) analysis of the fat extracted fleshing and composite material was carried out to find out the responsible functional groups during the bonding of the composite. The data spectra were noted between the wavelength of 400 and $4000 \mathrm{~cm}^{-1}$.

Table II. Composite fabrication ratio of FG, resin and hardener

\begin{tabular}{ccc}
\hline Sample ID & Fleshing ground $(\mathrm{g})$ & Ratio (resin: hardener) \\
\hline A & 60 & $20: 10$ \\
B & 60 & $30: 15$ \\
C & 60 & $40: 20$ \\
D & 60 & $50: 25$ \\
E & 60 & $60: 30$ \\
\hline
\end{tabular}




\section{Scanning electron microscope (SEM) analysis}

The fabricated optimized composite was subjected to assess surface morphology through SEM (JEOL JSM-6490, USA)analysis. Firstly, the composite sample was placed on conductible carbon tape. The SEM was operated at an accelerated voltage of $20 \mathrm{kV}$. The photograph of the surface texture was captured at $500 \mathrm{X}$ magnifications.

\section{Results and discussion}

\section{Fabricated composite}

The composite fabricated with FG was prepared at different ratios of the chemicals in a batch-wise distribution.Fig. 1 shows the optimized fabricated composite (sample D)with FG, resin, and hardener ratio of 60:50:25.The optimized composite was rigid in nature, grey in color with a dry feel. The average thickness of the composite was $14.3 \pm 0.16 \mathrm{~mm}$. The surface of the composite could be made smooth.

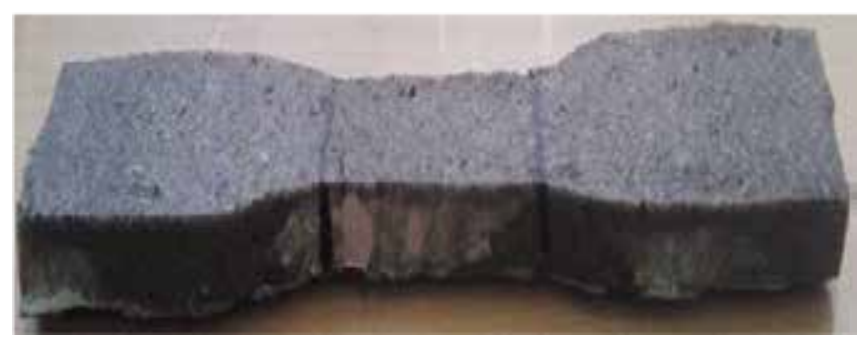

Fig. 1. Fabricated composite D (FG: resin: hardener = 60:50:25) at optimized conditions

\section{Physical and mechanical properties of composite}

The physical and mechanical properties of the composite have a direct influence on the quality of the composite. The fabricated composite was investigated for tensile strength, elongation at break (\%) and Young's modulus to verify the usability of the final composite.

\section{Tensile strength of composite}

The tensile strength property of the composite at various combinations is depicted in Fig. 2. Results indicate that for a fixed amount of FG (wt. $60 \mathrm{~g}$ ) with increasing the amount of mixture (resin: hardener-2:1) gradually tensile strength was increased. A lower amount of mixture (resin and hardener) e.g., A (FG: resin: hardener $=60: 20: 10)$, $\mathrm{B}$ (FG: resin: hardener-60: 30: 15), and $\mathrm{C}$ (FG: resin: hardener-60: 40: 20) did not provide good quality as a composite. The reason might be lack of proper bonding among the FG, resin, and hardener did not occur.

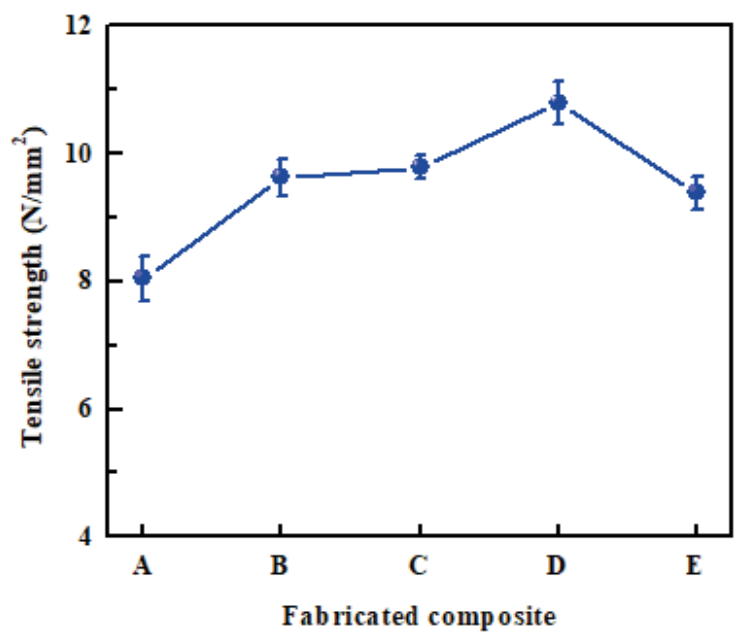

Fig. 2. Tensile strength of fabricated five different composites: A (FG: resin: hardener-60:20:10), B (FG: resin: hardener-60:30:15), C (FG: resin: hardener-60: 40:20), D (FG: resin: hardener-60: 50:25) and E (FG: resin: hardener-60:60:30)

For the combination of composite sample D (FG: resin: hardener-60: 50: 25), the tensile strength was maximum of $10.80 \pm 0.34 \mathrm{~N} / \mathrm{mm}^{2}$. In the case of composite sample E (FG: resin: hardener-60: 60: 30), the tensile strength was $9.4 \pm 0.3 \mathrm{~N} / \mathrm{mm}^{2}$. It seems that with increasing the amount of mixture (resin and hardener) e.g., sample E, for a fixed amount of FG (60 g), the tensile strength was decreased. It may be the reason is that, with increasing the amount of mixture (resin and hardener), resin and hardener were crosslinked each other nonetheless they did not bond with the fleshing granule, therefore, the tensile strength was decreased for the sample E (FG: resin: hardener-60:60:30). As a result, the ratio of $\mathrm{FG}$ : resin: hardener-60:50:25 was decided as the optimum ratio for the composite fabrication. 


\section{Elongation at break (\%)}

Fig. 3 shows the elongation at break (\%) at a varying combination of the composite. The elongation at break value of composite sample B was at maximum by $10.2 \pm$ $0.2 \%$. After that, elongation gradually decreased because, with an increased amount of mixture (resin and hardener), FG was strongly bonded with resin and hardener. For example, in composite sample D (FG: resin: hardener-60:50:25), elongation at break was minimum $(6.0 \pm 0.2)$. Further, with increasing the amount of mixture (resin and hardener), FG did not show a strong bond with the resin and hardener; therefore, elongation

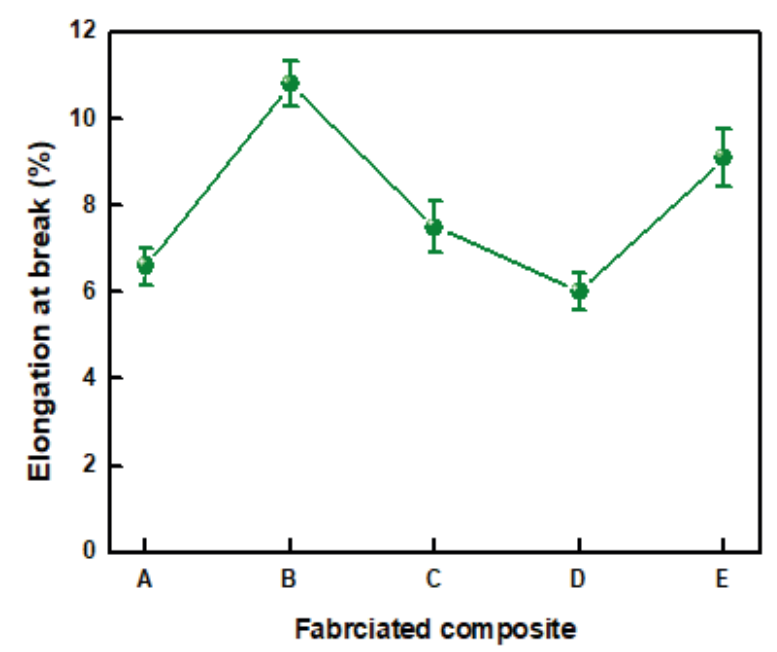

Fig. 3. Elongation at break of five different composites: A (FG: resin: hardener-60:20:10), B (FG: resin: hardener-60:30:15), C (FG: resin: hardener-60:40:20), D (FG: resin: hardener-60:50:25) and E (FG: resin: hardener-60:60:30).

was increased for sample $\mathrm{E}$ (FG: resin: hardener-60:60:30). The composite is going to be used as a rigid body with less elongation; therefore, the combination of the composite sample D was selected for the optimum composite fabrication process.

\section{Young's modulus}

Young's modulus (elastic modulus) measures the stiffness of solid material. The mechanical property, Young's modulus of the fabricated composites is depicted in Fig.4. It could be seen that Young's modu- lus of the prepared composite gradually increased with an increasing amount of mixture (resin and hardener). Young's modulus for the composite samples A (FG: resin: hardener-60:20:10), $\mathrm{B}$ (FG: resin: hardener-60:30:15) and C (FG: resin: hardener-60:40:20) were $93.8,101.4$, and $106.1 \mathrm{~N} / \mathrm{mm}^{2}$, respectively. In the case of fabricated composite sample D (FG: resin: hardener-60:50:25), Young's modulus was the highest $181.0 \mathrm{~N} / \mathrm{mm}^{2}$. After that, the value of Young's modulus was drastically deceased; composite sample D has the highest Young's modulus, which will show more rigidity under pressure during real-life application. The FG was strongly bonded with the resin and hardener, which showed the higher Young's modulus. Therefore, sample D where FG was bonded with resin and hardener

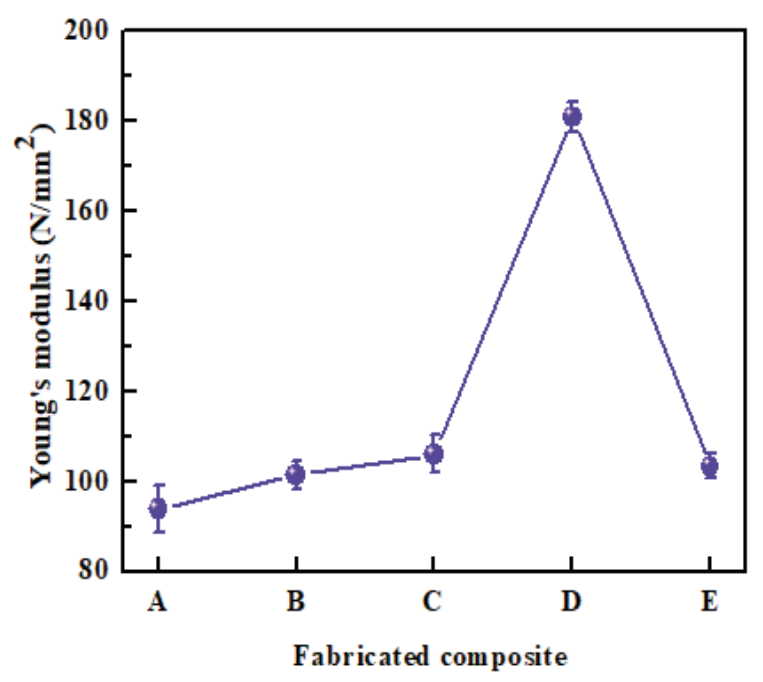

Fig. 4. Young's modulus of five different composites: A (FG: resin: hardener-60:20:10), B (FG: resin: hardener-60:30:15), C (FG: resin: hardener-60:40:20), D (FG: resin: hardener-60:50:25) and $\mathrm{E}$ (FG: resin: hardener-60:60:30).

strongly showed good Young's modulus.Sample E showed less Young's modulus because the higher amount of mixture (resin and hardener) did not crosslink with the FG but the resin and hardener crosslinked each other. 


\section{FTIR analysis}

Fig. 5 represents the FTIR analysis of the fat extracted fleshing and the fabricated composite. Before the fabrication, the fleshing shows strong stretching of $\mathrm{O}-\mathrm{H}$ and $\mathrm{N}-\mathrm{H}$, $\mathrm{C}-\mathrm{H}$ functional groups at 3350 and $2987 \mathrm{~cm}^{-1}$ wavelength, respectively. However, there is a sharp shifting of the functional groups $\mathrm{O}-\mathrm{H}$ and $\mathrm{N}-\mathrm{H}$, respectively, at 3689 and $2980 \mathrm{~cm}^{-1}$ wavelength after preparing the composite material. The medium stretching of the $\mathrm{C}-\mathrm{H}$ and $\mathrm{C}=\mathrm{C}=\mathrm{C}$ alkene group was found at $1917 \mathrm{~cm}^{-1}$. Some stretching and bending of different groups like $\mathrm{C}=\mathrm{C}, \mathrm{N}-\mathrm{H}, \mathrm{N}-\mathrm{O}, \mathrm{C}-\mathrm{H}$, $\mathrm{C}-\mathrm{O}$ were also peaked at $1631,1535,1431,1282,1026$ $\mathrm{cm}^{-1}$ wavelength of the fleshing sample. However, there was significant shifting in the transmittance after the composite was prepared. The prepared composite indicated peaks at $1793,1620,1020,785 \mathrm{~cm}^{-1}$ revealing $\mathrm{C}=\mathrm{O}$,

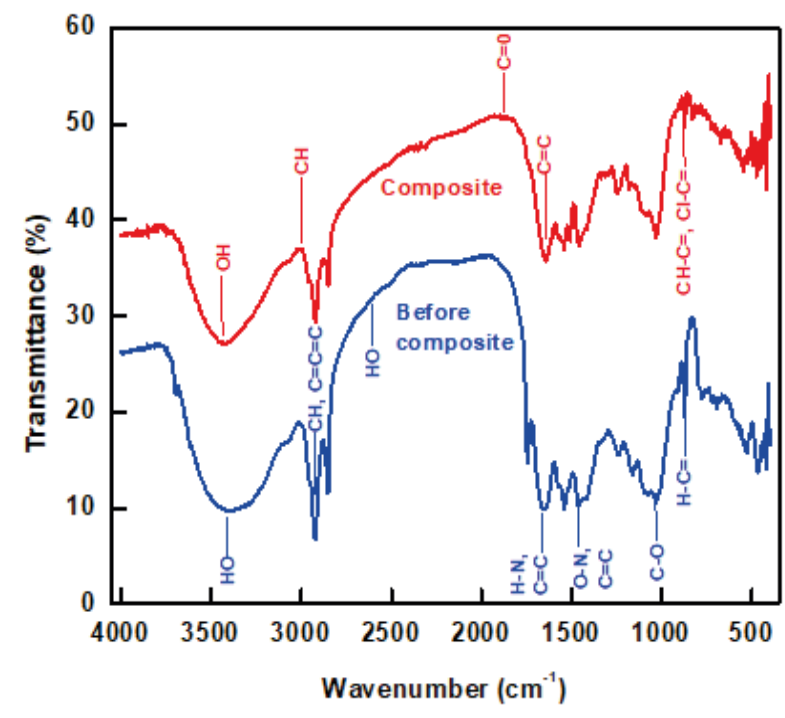

Fig. 5. FTIR spectrum of ground fat extracted fleshing and fabricated composited at optimized conditions

$\mathrm{C}=\mathrm{C}$, C-O stretching, and bending of $\mathrm{C}-\mathrm{H}$ groups. The significant change in the groups of the fleshing and the composite might be due to the breakage of the hydrogen bond present in the fleshing materials and rearrange them when compressed and sheared together during the fabrication process (Liu et al., 2019).

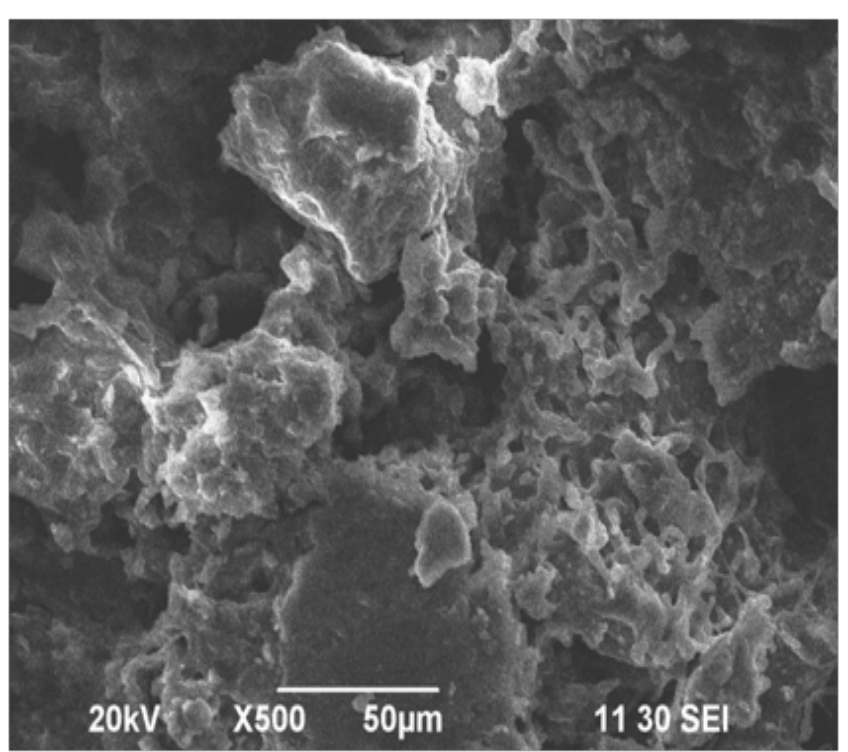

Fig. 6. SEM photograph of the fabricated composite D (optimized)

\section{SEM analysis}

SEM photograph of the final composite (sample D) is depicted in Fig. 6. SEM analysis showed that during the composite preparation, the fibers were properly attached with the resin and hardener. The reason might be because the fat extracted fleshing fiber can easily adapt with the epoxy resin matrix which indicates strong interface and wetting properties. Swain et al. (2016) also investigated the fiber alignment during the fabrication of the composite. The FG was dispersed uniformly in the resin and hardener matrix.

\section{Conclusion}

The study reveals to utilize the remaining fleshing parts after extraction of fat from the limed fleshing. The extracted fleshing material was fabricated with epoxy resin and hardener at a different ratio to produce a composite. The maximum compressive strength, elongation at break, and Young's modulus were found to be $10.80 \pm 0.34 \mathrm{~N} / \mathrm{mm}^{2}, 10.2 \pm 0.2 \%$, and 181.0 $\mathrm{N} / \mathrm{mm}^{2}$ respectively which indicates that the fabricated composite could be used in hardboard, leather products reinforcement, etc. The FTIR analysis expresses different functional groups which are responsible for bond 
formation. The SEM image of the composite reveals proper wetting and surface orientation of the fleshing fibers with the adhesive. The developed fabrication composites from fat extracted fleshing material provide dual utilization of the significant fleshing solid waste in tannery by employing the fat and remaining fleshing separately into two different valorized products. It could provide a solution to the environmental problems associated with the waste management of the leather industry.

\section{References}

Anupama P, and Rubina C (2013), Studies on the generation of biogas from collagen hydrolysate obtained from chrome shavings by alkaline hydrolysis: A greener disposal method, Research Journal of Recent Sciences 2: 234-240.

Dhal B, Thatoi HN, Das NN and Pandey BD (2013), ChemInform Abstract: Chemical and Microbial Remediation of Hexavalent Chromium from Contaminated Soil and Mining/Metallurgical Solid Waste: A Review, Journal of Hazardous Materials 250-251: 272-291.

Guduru RKR, Shaik SH, Tuniki HP and Domeika A (2021), Development of mono leaf spring with composite material and investigating its mechanical properties, Materialstoday: Proceedings 45(2): 556-561.

Hashem MA, and Nur-A-Tomal MS (2017), Valorization of tannery limed fleshings through fat extraction: An approach to utilize by-product, Waste Biomass Valorization 8(4): 1219-1224.

Kanagaraj J, Velappan KC, Babu NKC and Sadulla S (2006), Solid wastes generation in the leather industry and its utilization for cleaner environment-A review, Journal of Scientific and Industrial Research 65: 541-548.

Liu B, Li Y, Wang Q and Bai S (2019), Green fabrication of leather solid waste/thermoplastic polyurethanes composite: Physically de-bundling effect of solid-state shear milling on collagen bundles,
Composites Science and Technology 181: 107-674. DOI: 10.1016/j.compscitech.2019.06.001

Lupo R (2006), Fleshing treatment and compacting. Proc. of the IULTCS II. Euro Congress, Istanbul, Turkey, May 24-27.

Murugan K, Venkatesh S, Thirumalai $\mathrm{R}$ and Nandhakumar S (2021), Fabrication and investigations of kenaf fiber and banana fiber reinforced composite material, Materialstoday: Proceedings 37(2): 110-114.

Parvin S, Mazumder LT, Hasan S, Rabbani KA and Rahman ML (2017), What should we do with our solid tannery waste?, IOSR Journal of Environmental Science, Toxicology and Food Technology 11(04): 82-89.

Patel A and Patra DD (2014), Influence of heavy metal rich tannery sludge on soil enzymes vis-à-vis growth of Tagetes minuta, an essential oil bearing crop, Chemosphere 112: 323-332.

Polizzi C, Alatriste-Mondragón F and Munz G (2018), The role of organic load and ammonia inhibition in anaerobic digestion of tannery fleshing, Water Resources and Industry 19: 25-34.

Rai AK, General T, Bhaskar N, Suresh PV, Sakhare PZ, Halami PM, Gowda LR, and Mahendrakar NS (2010), Utilization of tannery fleshings: Optimization of conditions for fermenting delimed tannery fleshings using Enterococcus faecium HAB01 by response surface methodology, Bioresource Technology 101: 1885-1891.

Ravindranath E, Kalyanaraman C, Begum SS, and Gopalakrishnan AN (2010), Effect of recirculation rate on anaerobic treatment of fleshing using UASB reactor with recovery of energy, Journal of Scientific and Industrial Research 69: 790-793.

Ravindran B and Sekaran G (2010), Bacterial composting of animal fleshing generated from tannery industries, Waste Management 30: $2622-2630$.

Šanek L, Pecha J, Kolomaznik K and Barinova M (2015), Biodiesel production from tannery fleshings: 
Feedstock pretreatment and process modeling, Fuel 1148: $16-24$.

Sekaran G, Shanmugasundaram KA and Mariappan M (1998), Characterization and utilisation of buffing dust generated by the leather industry, Journal of Hazardous Materials 63: 53-68.

Sundar VJ, Raghavarao J, Muralidharan C and Mandal AB (2011), Recovery and utilization of chromium-tanned proteinous wastes of leather making: a review, Critical Reviews in Environmental Science and Technology 41: 2048-2075.
Swain SS, Samal SK, Mohanty S, and Nayak SK (2016), Investigation of fibre orientation using SEM micrograph and prediction of mechanical properties through micromechanical modelling, Bulletin of Materials Science 39(3): 837-846.

Tang P, Zhao Y and Xia F (2008), Thermal behaviors and heavy metal vaporization of phosphatized tannery sludge in incineration process, Journal of Environmental Sciences 20(9):1146-1152. 